\title{
ORFEO Y EURÍDICE EN EL SÉPTIMO ARTE
}

\author{
Ronald Forero-Álvarez \\ Universidad de la Sabana. Colombia \\ Lucio Martín Forero-Álvarez \\ Universidad Nacional de Colombia
}

Resumen: El presente artículo reúne las adaptaciones cinematográficas del episodio de Orfeo y Eurídice con el fin de establecer las transformaciones del mito y los diferentes objetivos de su inclusión en este tipo de obras. El análisis de las películas arrojó como resultado que cuatro plantean temas relacionados con el medio artístico (Orphée, Vous n'avez encore rien vu, Parking, Me ton Orfea ton Avgousto) y seis tratan problemáticas sociales (Orfeu Negro, Orfeu, The Fugitive Kind, Orpheus Descending, Evridiki BA 2O37, Shredder Orpheus).

Palabras clave: Mito - Cine - Adaptación - Orfeo - Eurídice

\section{ORPHEUS AND EURYDICE IN THE SEVENTH ART}

\begin{abstract}
This article gathers the cinematographic adaptations of the episode of Orpheus and Eurydice in order to establish the transformations and the different objectives of its inclusion in this type of works. The analysis of the films showed that four raise issues related to the artistic medium (Orphée, Vous n'avez encore rien vu, Parking, Me ton Orfea ton Avgousto) and six deal with social problems (Orfeu Negro, Orfeu, The Fugitive Kind, Orpheus Descending, Evridiki BA 2O37, Shredder Orpheus).
\end{abstract}

Keywords: Myth - Cinema - Adaptation - Orpheus - Eurydice

Recibido: 28.12.18 - Aceptado: 31.05.19 
Correspondencia: Ronald Forero Álvarez

Email: ronal.forero@unisabana.edu.co

Profesor Universidad de la Sabana. Colombia. Doctor en Textos de la

Antigüedad Clásica y su Pervivencia, Universidad de Salamanca.

ID ORCID: https://orcid.org/0000-0003-3276-0664

Correspondencia: Lucio Martín Forero Álvarez

Email: luforeroa@unal.edu.co

Historiador, Maestría en Escrituras Creativas,

Universidad Nacional de Colomba

ID ORCID: https://orcid.org/0000-0002-8344-1674

\section{Introducción}

$\mathrm{E}$ 1 descenso de Orfeo al Hades para rescatar a Eurídice y su fatal desenlace es, según se desprende de un análisis crítico de las fuentes, producto de una elaboración a partir del mitema de la catábasis y sus interpretaciones. En efecto, en las fuentes de época clásica se encuentran pocos motivos del mito. En la Alcestis (280392) de Eurípides se hallan evocadas la catábasis órfica y la persuasión de Perséfone, pues el tragediógrafo está interesado en resaltar los temas del amor, el sacrificio y la fidelidad entre esposos ${ }^{1}$. Para Platón (Smp. 179d) en su caracterización de Eros como inspirador del valor y del sacrificio en los amantes, Orfeo es un cobarde citaredo que no se atrevió a morir por amor y así permanecer junto con su esposa en el Hades, por lo que, a causa de la osadía de su descenso, recibió como castigo la muerte a manos de mujeres. Estas dos fuentes contrastan con la aún más breve evocación de Isócrates (11.8) quien apenas menciona que Orfeo sacaba muertos del Hades.

Los testimonios helenísticos hacen precisiones en los motivos y ofrecen interpretaciones y explicaciones del episodio, producto del interés de los escritores de la época en la erudición y los temas amorosos y etiológicos. Así, Hermesianacte en su Leontion (3.1-14) la llama Agríope y [Mosco] en su Canto fúnebre por Bión (122-125) se refiere a ella como Eurídice. Ps.Heráclito (21) tiene la particularidad de ofrecer una explicación

1 Otras tragedias de época clásica trataron el mito de Orfeo, pero no es posible saber cuáles eran los argumentos, debido a que apenas se conocen un par de líneas de dos tragedias de Aristias ( $\operatorname{Tr} G F$ I 5) y de Antífanes (fr. 180 Kock) que llevaban el título de Orfeo. 
racional del mito, pues, según el mitógrafo, cuando alguien ha salido ileso de viajes prolongados y de labores de riesgo, se dice que dicha persona ha salido sana y salva del Hades; de la misma manera, se dice que quienes logran superar momentos difíciles, caminos peligrosos y enfermedades graves han sido rescatados del Hades. Más interesante es el testimonio de Diodoro Sículo (4.25), que establece un paralelo entre la catábasis órfica con la de Dioniso, quien recuperó a su madre Sémele de los infiernos, una posible explicación de la inclusión del episodio en el mito de $\mathrm{Orfeo}^{2}$.

Las fuentes helenísticas no relatan el motivo de la pérdida de Eurídice, lo cual contrasta con las fuentes augústeas, en las que se encuentra la versión canónica — que incluye la muerte de Orfeo- y en la que la infracción de la lex impuesta por los dioses infernales de no mirar a su esposa hasta salir del inframundo juega un papel preponderante. Tal es el caso de Virgilio, la primera fuente latina en la que ya se encuentran todos los motivos del mito. Su inserción en la Geórgica IV (453-527) se enmarca en los contenidos y preceptos morales de la poesía augústea, en la que la piedad, las leyes y el orden ${ }^{3}$ concuerdan con los ideales de Octavio

2 De acuerdo con Graves (1985, pág. 123s.), los motivos del mito "parecen haber sido deducidos equivocadamente de pinturas que muestran la acogida de Orfeo en el Tártaro, donde su música encantó a la diosa-serpiente Hécate, o Agríope («rostro salvaje»), e hizo que concediera privilegios especiales a todas las ánimas iniciadas en los Misterios Órficos, y de otras pinturas que mostraban a Dioniso, cuyo sacerdote era Orfeo, descendiendo al Tártaro en busca de su madre, Sémele". La visión de González Delgado (2001, pág. 430) difiere: "el análisis de las versiones pre-virgilianas nos ha hecho sospechar que el mito literario de Orfeo y Eurídice tenía un final distinto al que nos ha legado Virgilio. El mito original estaría representado por un chamán heroizado conocido como Orfeo que viajaba a los infiernos a recuperar almas y, persuadiendo y convenciendo a los dioses gracias a su música, lograba que los dioses del otro mundo se las entregaran. La literatura fue vinculando esas almas genéricas con una específica: la de la mujer. Por paralelismos con otras historias del imaginario mítico griego, Orfeo descendía a los infiernos en busca de un ser querido. Éste, que en principio no tenía nombre, recibirá posteriormente el de Eurídice". Cfr. González Delgado (2008).

3 Representados en el sacrificio de Aristeo para resarcir su ofensa a Orfeo, en la falta que comete Orfeo contra el mandato divino y, sobre todo, en la vida en comunidad de las abejas, que viven en perfecta armonía, gracias a su respeto de las leyes y su rey, su piedad, su laboriosidad y su organización (149-228). 
para su reconstrucción de Roma. De hecho, el Emperador es mencionado al final de la composición como vencedor en la guerra y legislador divino $^{4}$. La versión que ofrece Ovidio (Met. 10-11.1-66) incluye todos los motivos del mito y se centra en los aspectos amorosos - el leitmotiv de las Metamorfosis-, pues la historia finaliza con el reencuentro de los amantes en el Hades después de la muerte de Orfeo y se observa el especial énfasis en el amor como causa de la catábasis, de la transgresión, de la fidelidad y de las historias de amor cantadas por Orfeo que ocupan la mayor parte del libro X.

Del s. I d. C., provienen dos evocaciones del mito en sendas tragedias sobre Hércules compuestas por Séneca. Dichas evocaciones siguen la versión canónica y su inclusión se explica desde la óptica del neoestoicismo: en Hércules loco (569-591) se hace énfasis en la lex divina promulgada por el mortis arbiter y en su estricto cumplimiento; y en Hércules en el Eta (1031-1099) el filósofo recrea el canto del poeta que hace referencia al sometimiento de los mortales al paso del tiempo y a la muerte, leyes que no pueden ser transgredidas a pesar de los esfuerzos de Orfeo y el poder de su canto ${ }^{5}$. También un par de evocaciones en dos epigramas de Marcial resultan de interés (Spect. 21.b y Ep. 14.165), pues se resalta su muerte — fue devorado por una osa - y su falta de confianza y paciencia en el amor.

De las otras fuentes posteriores ${ }^{6}$, resulta significativa una referencia al mito de Plutarco en su Erótico (Mor. 761e-f), pues concuerda con las asociaciones del mito con Alcestis que se encuentran en Eurípides y Platón

4 El epilio de un imitador de Virgilio, conocido como Culex, cuenta la historia de un mosquito que le reprocha a un pastor en un sueño el haberlo matado, pues su picadura lo había despertado cuando una serpiente estaba a punto de picarlo. El poeta evoca el mito (117-119; 268-295), haciendo énfasis en la trasgresión de Orfeo, para su descripción del mundo de ultratumba, que, a su vez, le sirve para explicar el culto de los Muertos (Rostagni, 1964, pág. 40).

5 En ambas tragedias el mito funge como reflexión de los actos de Hércules, quien, preso de sus aspiraciones divinas, se jacta de su catábasis, lo que incrementa el odio de Hera que lo hace enloquecer y matar a su esposa y a sus hijos; tampoco, a pesar de sus hazañas, puede escapar de los padecimientos de la muerte, aun cuando al final se produzca su apoteosis.

6 Las versiones de Conon (FGH 26 fr. 1.45.2), Pausanias (9.30.6) y [Apolodoro] (1.3.2) no presentan cambios significativos. 
y va en la línea de Ovidio, en cuanto que afirma que si los mitos sobre Alcestis, Protesilao y Eurídice tienen algo de credibilidad, sería en que Hades obedece únicamente a las órdenes de Eros. Esta referencia también armoniza con las palabras de Protesilao (Luc. DMort. 28) que esgrime como argumento ante Perséfone y Plutón que ellos entregaron a Eurídice y a Alcestis por amor, de ahí que por la misma razón deberían entregarle a su esposa.

Las dos últimas fuentes de la Antigüedad ${ }^{7}$ que resultan relevantes en esta exposición son las de Fulgencio y Boecio, por sus interpretaciones alegóricas que influirán las de la Edad Media en adelante (González Delgado, 2001; 2008). Para el primero (Myth. 3.10), el mito de Orfeo es una fábula que representa el arte musical, en la medida en que hay dos habilidades en él: el poder de la voz que conmueve a la audiencia (Orfeo) y la mística armonía de los tonos (Eurídice), que es perseguida por los mejores, es decir, por los que buscan los secretos de la armonía (Aristeo) . $^{8}$ Para el segundo (Consol. 3.M.12.1-58), el mito ha de entenderse como una reflexión espiritual sobre el día del juicio final, pues quien mire hacia atrás en dirección a los infiernos perderá lo superior que lleva consigo.

El análisis anterior de las fuentes antiguas nos ayuda comprender la riqueza del mito y sus posibilidades de interpretación, pues cada autor, dependiendo de sus intereses y sus horizontes de expectativas, resalta uno o varios motivos del mito. Este mismo procedimiento puede observarse en las distintas recreaciones, alusiones y evocaciones que se encuentran en las manifestaciones artísticas en las que el episodio de Orfeo y Eurídice ha gozado de gran fortuna ${ }^{9}$. En este artículo nos centraremos en las adaptaciones del episodio de Orfeo y Eurídice en el cine, con el fin de ofrecer una visión de conjunto, complementar estudios previos y presentar películas poco estudiadas o de difícil acceso ${ }^{10}$. La presentación de las

7 Para un recuento de la presencia del mito en obras posteriores no solo literarias, cfr. Summers (1993) y Crocci da Graça y Mínguez Baños (1995).

8 Esta interpretación pertenece a Friedman (2000, pág. 98). Fulgencio, por su parte, también apoya dicha interpretación en su análisis etimológico de los nombres de los personajes del mito: Orfeo es denominado 'oreafone', es decir, 'optima uox'; Eurídice, 'profunda diiudicatio'; y Aristeo, 'ariston'.

9 Cfr. nota 7.

10 Especialmente el estudio de Ehrlich (2003) que examina en detalle seis 
películas tendrá en cuenta un criterio eminentemente temático que permite contextualizar mejor la utilización del mito. De esta manera, se expondrán en dos grupos: el primero conformado por las cuatro obras que tratan temas relacionados con el medio artístico (Orphée, Vous n'avez encore rien vu, Parking, Me ton Orfea ton Avgousto); el segundo, con las seis que abordan distintos tipos de problemáticas sociales (Orfeu Negro, Orfeu, The Fugitive Kind, Orpheus Descending, Evridiki BA 2037, Shredder Orpheus). La parte final del artículo estará dedicada a las conclusiones en las que se incluye un cuadro cronológico de las películas analizadas con los datos que se han omitido en la presentación de las películas (director, guion y país).

\section{Orphée (1950)}

La primera película dedicada al episodio de Orfeo y Eurídice es Orphée, la segunda secuela de la trilogía órfica de Jean Cocteau ${ }^{11}$. El filme resalta por su montaje cinematográfico surrealista, en cuanto que sus efectos visuales pretenden generar un carácter sobrenatural en sus personajes y en la narrativa, con el fin de resaltar los tres temas básicos que, en palabras del propio Cocteau (2015, pág. 132), son los siguientes: “1. Las sucesivas muertes por las que tiene que pasar un poeta hasta llegar a ser como dice el admirable verso de Mallarmé 'Tal y como la eternidad lo transforma en sí mismo'. 2. El tema de la inmortalidad: la persona que representa la Muerte de Orfeo se sacrifica, se anula para hacer inmortal al poeta. 3. Los espejos: en ellos nos vemos envejecer. Nos acercamos a la muerte".

Dichos temas se manifiestan en los personajes y en la compleja estructura diegética en la que la realidad puede ser manipulada y convertida en un sueño. Tal es el caso de la Princesa — personificación de la muerte, la inspiración y la crítica (Bernstock, 1991, pág. 165)—, dueña de una editorial que financia la obra de Cégeste, un joven poeta antipático y

películas: Orphée (1950), Orfeu negro (1958), Orfeu (2000), Ugestu (1953), Vertigo (1958) y El amor brujo (1986). En las tres últimas no hay una referencia al mito, pero le interesan a la autora porque se encuentra presente el mitema de la catábasis. Excluimos de este estudio la película Sakura, Futatabi no Kanako (2013) porque no está basada en el mito, aunque dicho título fue traducido al inglés como Orpheus 'Lyre. Se trata de una madre que perdió a su hija y cree que ha reencarnado en la hija de una adolescente, cfr. Schilling (2013).

11 La primera, Le sang d'un poète (1930), está dedicada exclusivamente a Orfeo; la tercera es Le testament d'Orphée (1960), cfr. nota 12. 
borracho, reflejo y contraposición de Orfeo y sus ansias de fama. Orfeo se enamora inevitablemente de ella en medio de los acontecimientos que rodean la muerte y la resurrección de Cégeste, ambos sucesos propiciados por la misma Princesa, que le revela a Orfeo su poder al 'despertar' a Cégeste y conducirlo al inframundo a través de un espejo. Heurtebise, conductor y ayudante de la Princesa, también hace evidente su poder en la escena en la que lleva a Orfeo al más allá para buscar a Eurídice, por medio del espejo de su habitación matrimonial. También, cuando la Princesa, ante la imposibilidad de estar con Orfeo, le ordena hacer retroceder el tiempo a Heurtebise para cambiar el curso de la historia, convirtiendo todo en un sueño de Orfeo, pues él muere a manos de los seguidores de Cégeste que lo acusan de su desaparición.

Cocteau también está interesado en presentar sus conflictos personales e intelectuales ante el proceso creativo ${ }^{12}$, como el versátil poietes que fue durante su vida artística, en sus facetas como poeta, grafista, diseñador, dramaturgo y cineasta. De manera que el entramado amoroso que se presenta en la película es una representación de tales conflictos, así como de su creencia en que los verdaderos poetas deberían vivir precariamente balanceándose entre este mundo y el otro para poder encontrar la inspiración; también en que el poeta es una especie de mártir que sufre a manos de un público no comprometido con los planteamientos de su obra (Bernstock, 1991, pág. 165). Así, la Princesa, enamorada de Orfeo y celosa del embarazo de Eurídice, ordena su muerte. Orfeo baja al inframundo para recuperar a su esposa, pero en realidad es una excusa para reunirse con la Princesa. Por otra parte, están presentes en la película alusiones a los horrores de la Segunda Guerra mundial, ya que, siguiendo a Ehrlich (2003, págs. 70-71), los motociclistas vestidos de negro que deambulan por París están al mando de la Muerte, cuyas órdenes la llevan a juicio a ella y a Heurtebise, quien también se ha enamorado de Eurídice. Una corte blanda ordena que la Princesa y Heurtebise queden, a pesar de sus actos, en libertad bajo fianza y que Eurídice y Orfeo regresen a la vida con la condición de cumplir con la lex. A su vez, la ambición de Orfeo lo endurece ante el daño que está infligiendo a los demás, pues su búsqueda

12 Tema tratado a lo largo de su trilogía órfica desde distintas perspectivas. De hecho, Le Testament d'Orphée es una película autobiográfica, protagonizada por el mismo Cocteau, que retoma los temas y personajes de su Orphée con un tratamiento similar, pero incluyendo el tema del Séptimo Arte. 
obsesiva de la Princesa, es decir, de la inspiración y la fama, lo lleva a rechazar a Eurídice y causarle su muerte definitiva al infringir la lex cuando la observa a través de un espejo.

\section{Vous n'avez encore rien vu (2012)}

Otra película relacionada con la reflexión en torno a la actividad artística es Vous n'avez encore rien $v u$, cuya estructura diegética, como se verá más adelante, permite el tratamiento no solo de la importancia del constante ejercicio crítico (Caillard, 2012), sino también de las vicisitudes del amor que se enfrenta a la mentira, al engaño, a los celos y a los fantasmas del pasado, pero también al perdón.

El filme es una adaptación de la obra de teatro Eurydice (1941) del dramaturgo francés Jean Anouilh, en la que el episodio del mito es una narración enmarcada, introducida al entrelazar la proyección de la obra de teatro Eurydice ${ }^{13}$ en la historia principal. Dicha historia es la de los días finales de Antoine d'Anthac, director de la compañía de teatro que puso en escena la obra de teatro en cuestión. El director cita al elenco de su obra a través de un notario que les notifica su muerte y los invita a asistir a su mansión en un pueblo lejano para leer su testamento. Los actores, envejecidos, cumplen la cita y el notario procede a leer el acta, que establece que los presentes tienen que ver la última versión de Eurydice, realizada por una joven compañía de teatro. Acomodados en una sala de vídeo, los asistentes comienzan a ver la proyección para cumplir la última voluntad de su antiguo director. Antoine aparece en la proyección y les pide que realicen comentarios y correcciones, pues no alcanzó a hacerlos por su repentina muerte. A medida que pasa la proyección, los actores empiezan a rememorar los diálogos de la obra, de manera que las historias y las generaciones se entrelazan.

En cuanto al episodio mítico, sus motivos son modificados para introducir un conflicto amoroso. Orfeo es un violinista que toca en una estación de tren. Eurídice se enamora de él a primera vista, sin importarle su compromiso con Mathias, el cual fue una imposición de sus padres. Impulsada por su nuevo amor, Eurídice le confiesa a Mathias que no lo ama, provocando así su suicidio. Como contraste de este fatídico suceso, el amor

13 La adaptación de la obra de Anouilh difiere en pocos aspectos de la que se presenta en la película. Solo un cambio es significativo: en la obra de teatro Eurídice y el director eran amantes antes de su romance con Orfeo. 
entre Orfeo y Eurídice se fortalece y viven un romance en la habitación de un hotel. No obstante, Henri, un hombre misterioso, le entrega una carta a Eurídice, tras despistar a Orfeo. La carta la envía Dulac, un antiguo amante de Eurídice. Sintiéndose culpable por haberle jurado a Orfeo que no había tenido amantes antes de Mathias, la joven decide marcharse y toma un autobús. Orfeo no sospecha nada y cree que Eurídice va a traer la cena, pero el autobús sufre un accidente en el que ella muere. Dulac aparece en medio del duelo de Orfeo y le confiesa el amorío que tuvo con Eurídice; también le advierte que ella fue una mujer inestable, producto de su juventud. Después de la conversación, Henri aparece nuevamente y le ofrece a Orfeo revivir a Eurídice al instante, con la condición de no voltear a mirarla, hasta el amanecer. Orfeo acepta y Eurídice revive, pero la pareja no deja de discutir por las mentiras y los celos, convirtiéndose su relación en un 'infierno'. Orfeo no soporta estar con ella y decide mirarla. Ella muere y Orfeo entra en depresión por su decisión. Una vez más, Henri aparece y le ofrece a Orfeo la posibilidad de reencontrarse con ella, pero para ello debe estar dispuesto a morir. Orfeo acepta y es trasladado a un bosque lejano e inhóspito donde se encuentra con Eurídice.

Una vez terminada la proyección de la obra de teatro, el notario les señala una puerta por donde ingresa Antoine y les ofrece disculpas por fingir su muerte para reunirlos. Una semana después, aparece en el periódico la noticia de la muerte misteriosa de Antoine en un lugar lejano. En el funeral aparece la protagonista de Eurydice, aunque se esconde de los asistentes al entierro, entre ellos los actores de la obra. Este final es también una transposición de la obra y del mito en la trama de la película, que permite la mezcla de la ficción y la realidad, del cine y el teatro, del pasado y el presente, de la vida y la muerte (Trémois, 2012, pág. 129), pues tanto Orfeo como Antoine se dirigen al mismo lugar para llegar al otro mundo. Orfeo se reencuentra con Eurídice, pero el director muere antes de reunirse con la actriz que personifica a Eurídice en la última versión de la obra de teatro. Sin embargo, Eurídice se reúne con el director en la premier de Eurydice en un teatro parisino, encuentro que cierra la película con el mismo diálogo en voz en off de la obra de teatro proyectada "-¿Podrá mirarme? -Sí, sin temor a perderte". 


\section{Parking (1985)}

Relacionada también con el medio artístico se encuentra Parking, cuya adaptación del mito sirve para tratar el tema del amor, la sexualidad y la fama en la década de los ochenta, en la que el exceso en el uso de las drogas era un problema recurrente. En este contexto, Orfeo es un famoso cantante de pop ${ }^{14}$ que compone canciones de amor a Eurídice, una artista y diseñadora que trabaja para Orfeo en el diseño de las portadas de sus discos. Aun cuando está dispuesto a descender a los infiernos para rescatar a Eurídice, Orfeo se siente atraído por Calais — uno de los Argonautas convertido aquí en su productor e ingeniero de sonido- a quien besa apasionadamente después de un concierto y con quien habla de los sentimientos del uno hacia el otro. El tratamiento de la sexualidad en personajes con este tipo de orientaciones sexuales, diferentes a las socialmente aceptadas, causó que la película no fuera bien recibida por la prensa conservadora (Mulligan, 2017, pág. 147), pues la epidemia de VIH que se vivió en los ochenta fue asociada al homosexualismo.

El tema de las drogas se trata a través del personaje de Eurídice que muere de una sobredosis de heroína tras una fuerte discusión con Orfeo por el consumo de drogas. Ante el suicidio de Eurídice, Orfeo decide bajar de nuevo ${ }^{15}$ a los infiernos con la ayuda de Perséfone, quien le exige la firma de un contrato de confidencialidad para que no revele los sucesos que tendrán lugar a continuación. Esta segunda catábasis sirve para introducir los

14 Una mezcla entre Mick Jagger y John Lennon (Schidlow, 1985; Darren, 2016, pág. 101), como sugieren su modo de vida y su muerte.

15 La primera catábasis tiene lugar cuando Orfeo muere al electrocutarse accidentalmente cuando tocaba su guitarra en el ensayo previo al más importante concierto de su carrera en París. A su llegada al infierno, al que se entra por la pared de un 'parking', aparece Caronte para conducirlo ante la presencia de Hades — gerente de una fábrica—, quien le comunica que su muerte ha sido un error y que está programada para después. Hades entonces le ordena a Perséfone, su asistente, resucitar a Orfeo y le pide a Orfeo que no hable de lo que sucedió. Orfeo regresa a la vida, pero es vigilado por Perséfone, pues Hades no confía en la palabra del cantante. En efecto, Orfeo, perplejo por lo sucedido, le cuenta a su asistente que ha tenido un sueño e intenta explicar que estuvo en el inframundo. Esta primera catábasis está inspirada en el Orphée de Cocteau, película a la que se hacen algunas referencias más en aspectos puntuales como la tipografía usada en los carteles del concierto de Orfeo, que recuerda el estilo caligráfico preferido por Cocteau para algunos de sus créditos (Darren, 2016, pág. 100). 
motivos convencionales del mito. De esta manera, Hades, quien no soporta la presencia de Orfeo, decide imponer una cláusula más en el contrato de confidencialidad en el inframundo, la cual representa la lex que será infringida cuando Orfeo intente auxiliar y darle ánimos a Eurídice en el camino de regreso a la vida. Orfeo, impotente, comienza a componer una canción para ella, la presenta en un gran espectáculo y al final del concierto es asesinado por una mujer que pertenecía a su club de fans, llamado Club des Bacchantes, que están furiosas por habérseles negado entradas gratis al concierto de París. Finalmente, Orfeo y Eurídice se reencuentran en el inframundo y hacen el amor.

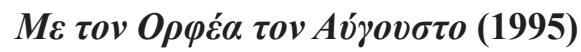

Una última película está relacionada con la vida de los artistas. Se trata de Me ton Orfea ton Avgousto (Con Orfeo en agosto), en la que se hace especial énfasis en el tema de la música, la ambición y la obsesión que puede llegar a producir, pues está presente a lo largo de toda la obra por medio de melodías y canciones que están estrechamente relacionadas con la acción. También los protagonistas refuerzan el tema musical, pues Eurídice es una cantante de un grupo de música popular y Orfeo es un pastor de ovejas que tiene un talento excepcional para tocar el clarinete. La historia gira en torno a la obsesión que tiene Panos, un rico comerciante, con la voz de Eurídice, a quien quiere convertir a toda costa en una gran estrella en Atenas. De hecho, la película inicia con la aparición de Panos, quien conduce un carro bajo una tormenta escuchando y cantando emocionado la canción — compuesta ad hoc- que aparecerá nuevamente en la película y que es interpretada por la propia Eurídice: 


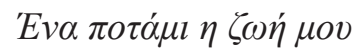

$\pi$

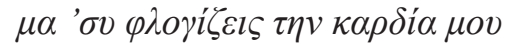

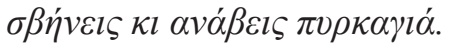

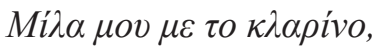

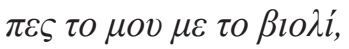

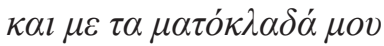

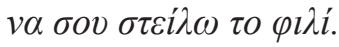

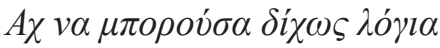

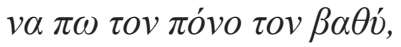

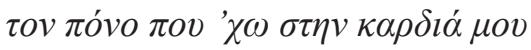

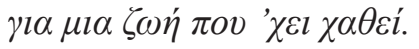

Un río es mi vida

que canta en el barranco,

pero tú abrasas mi corazón,

apagas y enciendes fuego.

Háblame con el clarinete,

dímelo con el violín,

y con mis pestañas

te enviaré el beso.

¡Ay!, ojalá pudiera sin palabras

expresar el dolor profundo, el dolor que tengo en mi corazón por una vida que se ha perdido.

La canción es especialmente significativa, pues está relacionada con los personajes y anuncia a manera de oráculo los acontecimientos que sucederán a continuación. Asimismo, es una alusión al episodio del mito de $\operatorname{Pan}^{16}$ en el que persigue a la ninfa Siringa, quien ante el acoso se lanzó al río Ladón, pidió ayuda a sus hermanas y fue convertida en un cañaveral ${ }^{17}$. El clarinete representa a Orfeo que habla únicamente a través de su instrumento y que empieza a formar parte del grupo cuando Kyriakos, el anterior clarinetista, debe partir. Desde ese momento las miradas entre Orfeo y Eurídice manifiestan el amor que ha surgido entre ellos. No obstante, la continua insistencia de Panos finalmente convence a Eurídice de irse a Atenas con él. Ya en la metrópolis las promesas de Panos no se cumplen y su afición al juego y su gusto por los ambientes sórdidos convierten la vida de Eurídice en un 'infierno'. Cuando Eurídice camina sin rumbo y con la mirada perdida en medio de prostitutas y habitantes de calle, aparece (la imagen de) Orfeo en un callejón tocando el clarinete ${ }^{18}$.

16 Nótese el parecido entre los nombres de Pan (Пóvas) y Panos y la similitud con la versión virgiliana en la que el acoso de Aristeo provoca la muerte de Eurídice.

17 Pan abrazó las cañas y el hermoso sonido que salió de ellas le inspiró la creación del instrumento que lleva el nombre de la ninfa.

18 Acompañado de su perro negro, que aparece en la primera escena en que Orfeo y Eurídice se encuentran. El can se presenta como si fuera el guardián de una puerta por la que pasa el pastor, en clara alusión a Cerbero. La escena, que 
Ella camina hacia él y la escena cambia a la del grupo nuevamente reunido, pero con una evolución manifiesta: la música de Orfeo ha transformado al grupo que 'hechiza' a una audiencia cada vez mayor. Panos reaparece arruinado y desesperado para raptar a Eurídice en un carro. Los demás miembros del grupo, incluido Orfeo, intentan ayudarla, pero logra su cometido con la ayuda de sus esbirros. En la huida se produce un grave accidente con una cosechadora. Finalmente, aparece Orfeo en el lugar del siniestro tocando su clarinete para tratar de mantener con vida a Eurídice.

\section{Orfeu Negro (1959)}

Con Orfeu Negro, inspirada en la obra de teatro Orfeu da Conceição: Tragedia Carioca (1956) de Vinícius de Moraes, empiezan las películas a tratar temas sociales, pues este filme aborda el mito en un contexto carnavalesco que contrasta con las precarias condiciones sociales de las favelas de Río de Janeiro, y en el que la apatía de la sociedad ante la desgracia ajena y la falta de control de las emociones son temas preponderantes (Lee, 1961; González Delgado, 1999, pág. 340). En consecuencia, en esta adaptación del mito, Orfeo es, a pesar de su talento para la música, un conductor de tranvía que se ve obligado a comprometerse con Mira por su obsesión hacia él. Eurídice, de cierta manera padece una situación similar, en cuanto que es una joven que llega a Río escapando de un hombre que la persigue para matarla ${ }^{19}$. A pesar de las circunstancias, Orfeo conquista a Eurídice con una canción y su propia versión poética del mito: "Miles de años atrás, Orfeo estaba triste y melancólico como este pajarito encerrado en su jaula. Un día de las cuerdas de su guitarra le hablaron de un único amor, de los besos perdidos en los labios de Eurídice. Y los labios de Eurídice se entreabrieron con ansiedad y la flor perfumada se abrió silenciosamente".

El fallecimiento de Eurídice, causado involuntariamente por Orfeo, pero propiciado por la persecución de la Muerte, abre paso a los motivos de la catábasis y la muerte de Orfeo. En efecto, la Muerte se lleva el cadáver

tiene lugar en un valle, también es premonitoria de los hechos futuros, ya que Eurídice cuando contempla su rostro en el río observa imágenes del final.

19 El sujeto está caracterizado como si se tratara de una personificación de la muerte, pues está representado por un hombre disfrazado a manera de esqueleto y de actuación sigilosa, un personaje típico de los carnavales en los que el tema de la muerte (y la resurrección) es recurrente (Bakhtin, 2003, pág. 8). 
de Eurídice en una ambulancia, mientras Orfeo yace inconsciente por un golpe propinado por este personaje, cuando aquel intentaba auxiliar a Eurídice. Una vez que Orfeo recobra el conocimiento, la busca por todas partes en compañía de un amigo, recibiendo siempre una respuesta indolente, incluso en los hospitales y en una estación de policía, a pesar de su evidente desesperación. Su búsqueda, por tanto, se ha convertido en un 'infierno'. Finalmente, un empleado lo conduce a una casa custodiada por un perro llamado Cerbero que solo permite la entrada de Orfeo al lugar. Allí se celebra un ritual candomblé (Ehrlich, 2003, pág. 72) ${ }^{20}$, en el que Orfeo participa cantando con otras mujeres para comunicarse con Eurídice. La ceremonia funciona y logra escuchar la voz de Eurídice que como una orixá ha tomado posesión del cuerpo de una de las ancianas que ha entrado en trance (Arrieta Domínguez, 2014, pág. 139). Orfeo la busca mirando alrededor sin éxito; Eurídice, entonces, le advierte que si mira hacia atrás la perderá para siempre. Orfeo insiste en encontrarla, aun cuando Eurídice le pregunta si no es capaz de amarla con solo escucharla. Después de incumplir la lex y perder a Eurídice, Orfeo recupera el cuerpo de su amada de la morgue, llevándolo a la favela para enterrarlo, pero al llegar Mira, encolerizada, lanza una roca que choca en su cabeza y este cae junto a Eurídice al abismo que desemboca en la urbe.

\section{Orfeu (1999)}

Aunque Orfeu es también una adaptación del Orfeo de Vinícius de Moraes, se diferencia del Orfeu Negro en que se enfoca ${ }^{21}$ en el drama de la corrupción, la violencia y la pobreza que azotan las favelas de Río de Janeiro; de ahí que la acción tenga lugar en los años noventa y no en los

20 De acuerdo con Carneiro Araújo (2016, págs. 15-16), existe una estrecha relación entre las religiones afrobrasileñas, especialmente el candomblé, y el carnaval, relación que siempre ha existido por sus orígenes comunes, pero que, no obstante, presentan puntos de tensión y de conflicto, debido a que los diferentes actores sociales que administran tanto la religión como el carnaval presentan concepciones diferentes en cuanto a los límites y las fronteras que se supone que existen, o incluso que se cree que deben existir, cuando se encuentran elementos de estos dos universos (el religioso y el lúdico).

21 Temáticas enmarcadas en el compromiso social del Cine Novo (Cadvid, 2001), movimiento del cual Carlos José 'Cacá' Fontes Diegues fue uno de sus fundadores. 
cincuenta. De manera que el argumento y los personajes presentan algunos cambios. Eurídice acaba de llegar a Río de Janeiro tras el asesinato de su padre en una mina de oro del Amazonas. Mira es una modelo hermosa y ambiciosa que, a pesar de sus encantos, no puede evitar el enamoramiento de los protagonistas. Orfeo es un joven cantante y compositor de samba cuyas canciones han hipnotizado a las audiencias más allá de la favela donde vive, especialmente en el carnaval. Podría permitirse el lujo de cambiar sus precarias condiciones de vida, pero prefiere quedarse fiel a sus raíces, pues tiene la intención de cambiar la situación de la favela por medio de su música. Su ánimo de pacifista y de protector de su comunidad (Ehrlich, 2003, pág. 70) lo lleva a desafiar a Lucinho para que abandone la favela, so pena de denunciarlo ante los medios de comunicación que cubren el carnaval, puesto que es el líder de una pandilla de la favela que recluta y vende estupefacientes a los niños y jóvenes. No obstante, Lucinho es ahijado del sargento Pacheco, quien está al mando de la estación de policía local. Así, la fuerza de seguridad que representa al estado pasa a ser cómplice de los delincuentes, ya que captura únicamente a los consumidores de droga, dejando en la impunidad a los verdaderos responsables. La corrupción del sargento Pacheco se explica desde su perspectiva sobre los pobres que habitan la favela, pues, para él, la pobreza es un problema que se arregla con la esterilización, no mediante el mejoramiento de la sociedad en el que la aplicación de la ley juega un papel decisivo. Lucinho responde al desafío de Orfeo acosando a Eurídice, a quien asesina involuntariamente. Orfeo, sin saber lo ocurrido, la busca en la favela para irse a vivir juntos a otro lugar. Su búsqueda infructuosa representa un primer intento de rescate de Eurídice del 'infierno' en el que se ha convertido la favela. Mientras Orfeo está con su padre hablando de la desaparición de Eurídice, un anciano habitante de calle le dice que Lucinho tuvo que ver con su desaparición. Orfeo entra en cólera y va a la guarida de Lucinho; este lo recibe alicorado y drogado. Confiesa que él la mató sin querer y arrojó el cuerpo en un basurero que está abajo del morro y que colinda con la ciudad. Orfeo baja por el abismo, no sin antes darle un beso en la boca a su amada y matar a Lucinho de un tiro. Entonces, Orfeo realiza una segunda catábasis para buscar el cadáver de Eurídice. Al llegar a la favela con Eurídice en brazos, se encuentra con la policía que lo busca por la muerte de Lucinho. Después de la muerte de Orfeo a manos de Mira, Orfeo y Eurídice hacen parte de una comparsa y desfilan por el Sambódromo. 
La religión al igual que en Orfeu Negro está presente por su estrecha relación con el carnaval y está representada por Conceição, la madre de Orfeo, quien tiene el papel de oráculo, aunque no interrumpe ni habla con nadie de lo que pasará. Su papel es pasivo, pero su rol se hace evidente por los objetos que tienen relación con ritos religiosos. En las escenas finales intenta hallar al culpable de esta tragedia. Primero lo hace con Eurídice, como la mujer que hechizó a Orfeo y cambió su destino y luego culpa a Dios, de quién afirma que le tenía envidia a Orfeo, como si se tratara de uno de los antiguos dioses grecorromanos.

\section{The Fugitive Kind (1960)}

Siguiendo la línea de la presentación de problemas sociales, The Fugitive Kind, una adaptación de la obra de teatro Orpheus Descending (1957) del dramaturgo Tennessee Williams, aborda los problemas sociales causados por los grupos supremacistas blancos que surgieron en los Estados Unidos después de la derrota del Sur en la Guerra de Secesión. Este tipo de grupos ilegales promovían, además de la esclavitud, el racismo y otros tipos de exclusión como la xenofobia, el antisemitismo, la homofobia, el anticatolicismo y el anticomunismo, lo que llevó a la corrupción moral y a distintos tipos de violencia (Crowther, 1960; Palmer \& Bray, 2009, pág. 235). Estos antecedentes históricos son determinantes, no solo en el desarrollo de la trama — ambientada entre los años cuarenta y cincuenta-, sino también en la adaptación del mito. Esto se debe a que la impunidad y el encubrimiento en la muerte del padre de Lady Torrance a manos de los 'Vigilantes' 22 llenó su corazón de odio y desconfianza hacia todos los habitantes del pueblo, allanado el camino a un romance furtivo con un recién llegado al pueblo. Pero no sin razón, ya que este tipo de grupos al margen de la ley contaban con el apoyo de los sectores más conservadores de la comunidad y su poder de intimidación acallaba las voces de los habitantes, por lo que, desde la perspectiva de Lady, todos eran culpables, incluso su propio esposo, Jabe Torrance, con quien se casó al no tener más opción. De esta manera, la vida de Lady desde la muerte de su padre se había convertido en un 'infierno', al cual llega el joven y apuesto guitarrista Valentine, apodado 'Snakeskin' por su infaltable chaqueta de piel de

22 El padre muere incinerado en un incendio a su negocio provocado por este grupo supremacista, tras enterarse de que les había vendido licor a los afroamericanos de la zona. 
serpiente, quien había llegado recientemente al poblado después de purgar una condena en Nueva Orleans. Este músico con apariencia de 'Elvis' despertó inevitablemente la atención y el deseo de las mujeres del pueblo, especialmente de Carol Cutrere, quien lo acosaba a pesar de las negativas de Valentine. 'Snakeskin' insiste en trabajar en la tienda de ropa de Lady, debido a su interés en ella, lo que termina en una relación amorosa, de la cual sospecha Jabe, pero que no puede corroborar, pues sucede durante las constantes recaídas de una enfermedad que padece desde hace un tiempo. La relación hace que Lady vuelva a vivir, se sienta libre, se despierte nuevamente y satisfaga su libido, lo que le ayuda a sobreponer su pasado y sus conflictos internos (Rodríguez, 2010). Dado que el amor entre los amantes clandestinos crece, deciden hacer planes juntos. Uno de ellos el de abrir una confitería en memoria del padre de Lady. Cuando Jabe, recién recuperado de una recaída, se entera de la inauguración de la confitería, se enfurece $y$, en medio de una discusión, termina confesando que participó en la muerte del padre de Lady. Ella sale corriendo de la tienda y Jabe cae de nuevo enfermo. Entre tanto, Valentine es amenazado por el sheriff amigo de Jabe - para que abandone el pueblo. Él está decidido a marcharse, pero se entera de que Lady está embarazada de él. Los amantes siguen con sus planes, pero cuando Jabe se recupera incendia la confitería y asesina a Lady de un disparo cuando ella intentaba detenerlo. 'Snakeskin' procura rescatar a Lady del incendio, pero el sheriff con ayuda de los bomberos termina por empujar a Valentine hacia las llamas causando su muerte.

\section{Orpheus Descending (1990)}

La otra película basada en la mencionada obra de teatro de Tennessee Williams es Orpheus Descending, la cual, aun cuando no presenta cambios significativos en la estructura diegética de The Fugitive Kind, enfatiza aún más la problemática causada por los grupos supremacistas blancos. Por una parte, se menciona directamente al Ku Klux Klan como responsable de la muerte del padre de Lady. Por otra, Valentine es capturado por Jabe y otros supremacistas que visten el atuendo característico del Klan para incinerarlo vivo. Asimismo, son usadas palabras racistas, tales como 'nigger' o 'wop' para referirse despectivamente a personas de las comunidades negra e italiana, respectivamente. 


\section{Evridiki BA 2037 (1975)}

Por su parte, Evridiki BA 2037 estrenada en 1975 —el año siguiente a la terminación de la Dictadura de los Coroneles en Grecia- aborda el tema de los regímenes totalitaristas y los abusos de poder que padece la población civil, en especial las mujeres que, como muestra la película, están particularmente expuestas a todo tipo de vejámenes. Los bombardeos y los helicópteros que se escuchan en algunas escenas podrían ser enfrentamientos de la resistencia que se opone a la dictadura o las batallas finales que está enfrentando el régimen antes de su derrocamiento. Si bien no hay un tiempo definido para el desarrollo de los acontecimientos, se trata de un futuro cercano ${ }^{23}$. El título de la película proviene del código 'BA 2037' que identifica la casa en la que está recluida Eurídice, quien, además del sufrimiento que supone estar recluida y vigilada constantemente ${ }^{24}$, tiene que soportar humillaciones de los transeúntes que le tiran basura por la pequeña ventana de su habitación. Estas arbitrariedades representan la complicidad y los excesos que les son permitidos a los que están a favor del régimen dictatorial, que tiene aislada la población como medio de represión y control de sus contradictores. La protagonista también tiene problemas de memoria, producidos, según la versión oficial, por un 'accidente'. En medio de su aislamiento, trata insistentemente de recordar, sin éxito, su pasado aun cuando le es permitida la visita de una amiga que trata de ayudarle en el proceso. El fin de dicha visita es quizá obtener información de cuánto Eurídice ha sido capaz de recordar, ya que parece haber sido torturada, dado que tiene vendas en las muñecas. La aparición de Orfeo sugeriría un rescate de ese infierno, pero la modificación del mito causa un gran impacto en la audiencia, puesto que el héroe al servicio de una dictadura pasa a ser un villano que viola a la prisionera. No obstante, el violador en que se ha convertido Orfeo no queda sin castigo, puesto que

23 Fotiou y Fessas (2017, pág. 118) señalan que la mayor preocupación de Nikolaidis en todos sus largometrajes es el futuro de la sociedad y el cine, una preocupación que toma la forma de una pesadilla inminente. De hecho, Nikolaidis nombró la trilogía de la que forma parte nuestra película "To Schima tou Efialti pou Erchetai" (La forma de la pesadilla que viene). Las otras dos películas son las siguientes: Proini Peripolos (1987) y The Zero Years (2005).

24 Fotiou (2014, pág. 102) comenta sobre este aspecto que en el conjunto de películas de Nikolaidis la vigilancia está vinculada al fascismo y a la obsesión de los estados fascistas por el control de sus ciudadanos. 
Eurídice, en medio del delito, saca un cuchillo, lo mata, lo castra y corre por la casa con los testículos de Orfeo en sus manos. La escena recuerda la castración de Urano y su derrocamiento por parte de Cronos, que trajo la utópica Edad de Oro (Hes. Op. 109-126; Pl. Cra. 397e; Verg. G.4.4-7; etc.), una alusión que da a entender que pueden ser vencidos los opresores y los poderosos, y su derrota dará paso a tiempos mejores. La estructura circular de la película deja el final abierto, en la medida en que se vuelve la escena inicial, quedando el interrogante de si la historia se reinicia o se desarrollará de otra manera; si la historia es producto de la psique perturbada de Eurídice; etc.

\section{Shredder Orpheus (1990)}

Desde una perspectiva diferente, en Shredder Orpheus están presentes todos los motivos del mito, adaptados para hacer una crítica a la sociedad estadunidense ${ }^{25} \mathrm{y}$, en concreto, sobre la televisión y el control que ejerce sobre los televidentes. La trama de la película, enmarcada en el movimiento cyberpunk, se desarrolla en un escenario postapocalíptico en el que la gente vive marginada en contenedores. El narrador, Axel, es un veterano de la guerra contra las drogas en Centroamérica que sufre de una parálisis que no le permite caminar, por lo que se arrastra en un monopatín. Su condición, declara, es producto de una 'mutación exitosa' producida por el ambiente, no de una secuela de guerra, como las personas piensan. Los infiernos están representados por la Euthanasia Broadcast Network (EBN), dirigida por Hades y Perséfone. Los miembros de dicha cadena son todos muertos vivientes. La cadena está interesada en que una bailarina llamada Eurídice entre a formar parte de uno de sus programas, pues necesita a gente joven para continuar ejerciendo su control mental sobre la audiencia, a la que le roba la conciencia a través del televisor. Orfeo es el cantante y guitarrista principal de la banda de trash metal, llamada 'The Shredders' (Los Trituradores). La muerte de Eurídice se produce durante la fiesta de bodas, provocada por subordinados de la $E B N$ que se llevan su cadáver. No obstante, la pareja recibe como obsequio una lira eléctrica diseñada por Jimi Hendrix, que tiene poderes mágicos y que le servirá a Orfeo para intentar rescatar a Eurídice de la muerte. Los padres de Orfeo - Calíope y Apolo- son trituradores de documentos que representan los recuerdos de los muertos que entran al edificio de la $E B N$. La lex es impuesta por Hades

25 Durante el gobierno de Reagan, según Pencak (1999, pág. 307). 
— persuadido por Perséfone- en un concurso musical que está siendo transmitido en vivo. Después de su fallido rescate, Orfeo, triste, sigue tocando en la banda en la que su instrumento mágico causa un especial efecto en su audiencia. También se vuelve miembro de una pandilla, en la que recibe el alias de 'Divo'. Después de un sueño en el que recuerda a Eurídice y los momentos felices, piensa en rescatarla, pero, al no saber cómo, consulta a un oráculo, representado por una adivina que interpreta las cartas que un televisor revela. El segundo intento de rescate se lleva a cabo en un macabro programa de concurso, transmitido en vivo conducido por Hades y Perséfone- en el que Orfeo debe elegir entre dos puertas: una en la que se encuentra Eurídice y otra en la que se encuentra su muerte. Orfeo elige y de la puerta salen las Furias que le cortan la cabeza. Aparece Eurídice en escena, coloca la cabeza en su lugar y sale el espíritu de Orfeo y se abrazan. La película termina con la reunión de la pandilla que le rinde culto a Orfeo y que destruye la antena de transmisión de la $E B N$, emulando a Orfeo en su afán de desafiar las fuerzas que intentan prevalecer sobre el individuo y la sociedad.

\section{Conclusiones}

Desde la aparición de Orphée a mediados del siglo XX, el episodio de Orfeo y Eurídice se ha transformado con el fin de tratar diversas temáticas que pueden dividirse en dos grandes grupos: las asociadas con el medio artístico y las que se enfocan en las problemáticas sociales, como ya se anticipó en la introducción. Para lograr que el episodio mítico sirviera para tratar dichas temáticas, debieron operarse, siguiendo la terminología de Genette $(1989 ; 2001)$, transposiciones diegéticas y pragmáticas de los hipotextos virgiliano y ovidiano, en los que se encuentran las versiones más completas y conocidas del episodio. No destaca solamente la modificación de las inscripciones en el universo diegético (transposiciones heterodigéticas), sino también la de las motivaciones (transmotivaciones) y la valoración de las acciones (transvalorizaciones). Las más radicales son las de Orfeo como un policía al servicio de un régimen totalitarista que, aprovechándose de su posición de poder, viola a Eurídice (Evridiki $B A$ 2037). Esto se debe a que estas modificaciones rompen con las más convencionales en las que Orfeo es un músico excepcional que, a diferencia del mito, no tiene un efecto sobre la naturaleza o los dioses infernales, sino que ejerce un impacto casi mágico sobre su audiencia. Dicho impacto lo convierte en un objeto de deseo (The Fugitive Kind, Orpheus Descending, 
Shredder Orpheus, Me ton Orfea ton Avgousto) que, en los casos de Orfeu Negro, Orfeu y Parking, es la causa de su muerte por la obsesión que llega a despertar entre las mujeres. Asimismo, Orfeo como poeta (Orphée), actor y director de teatro (Vous n'avez encore rien $\mathrm{vu}$ ) sirve para reflexionar sobre los procesos creativos y críticos en el arte. En cuanto a Eurídice, su papel es principalmente secundario, a excepción de The Fugitive Kind, Orpheus Descending, Evridiki BA 2037 y Me ton Orfea ton Avgousto, en las que las tramas giran en torno a su sufrimiento. Hades y Perséfone no siempre aparecen personificados, pero resulta por lo demás interesante que sean retratados en cargos altos, como en el caso de jueces (Orphée) y dueños o gerentes de empresas (Parking, Shredder Orpheus) cuya imposición de la lex - tan importante en las fuentes antiguas por su misticismo- termina siendo, desde la perspectiva moderna, una parodia del ejercicio del poder y de la burocracia.

La supresión de personajes es posible porque, como en la Antigüedad, el motivo más fascinante del episodio es el mitema de la catábasis. De hecho, este motivo del episodio mítico presenta elementos fantásticos que pueden representarse de manera excelente en el Séptimo Arte. Esto se debe a que la representación de la catábasis requiere la descripción de los infiernos, para lo cual se utiliza una gran variedad de recursos que dan como resultado una riqueza audiovisual al momento de proyectarse. Algunas veces se representa de manera metafórica más de una vez en una sola película (Vous n'avez encore rien vu, Orfeu Negro, Orfeu, The Fugitive Kind, Orpheus Descending). De ahí que el Hades y sus entradas son representados de varias maneras. Sobresalen por su despliegue de imaginación la entrada a los infiernos a través de espejos en Orphée y los televisores en Shredder Orpheus, que se apoderan del alma de los televidentes borrando sus recuerdos, una alegoría de su poder de destrucción y manipulación. Pero el más recurrente es el infierno en el que se han convertido las sociedades plagadas de vicios, pues son incapaces de garantizar justicia, libertad o condiciones de vida dignas, a causa de la complicidad, debilidad, abuso e indolencia de sus instituciones o de la comunidad misma (The Fugitive Kind, Orpheus Descending, Evridiki BA 2037, Orfeu Negro, Orfeu, Shredder Orpheus, Me ton Orfea ton Avgousto). A pesar de ello, aún quedan espacios similares a los Campos Elíseos o Islas de los Bienaventurados, en los que la felicidad puede alcanzarse y son representados por el teatro (Vous n'avez encore rien $v u$ ) y el Sambódromo (Orfeu), lugares a donde llegan los protagonistas después de su muerte 
para realizar las actividades interrumpidas por la muerte.

Desde el punto de vista cinematográfico, es posible identificar dos estilos. El primero se enfoca en el desarrollo dramático. A este estilo pueden reconducirse Orfeu Negro, The Fugitive Kind, Orpheus Descending, Orfeu, Vous n'avez encore rien vu y Me ton Orfea ton Avgousto. El segundo estilo es el de cine de autor, caracterizado por la experimentación cinematográfica. A él pertenecen Orphée, Evridiki BA 2O37, Parking y Shredder Orpheus. Así, en Orphée Cocteau utiliza el cine como la herramienta para presentar su visión del poeta en relación con el proceso creativo, lo cual se evidencia en su forma de hacer cine, ya que su labor de director y guionista la realizó de manera empírica. Gracias a esta continua experimentación, logró encontrar un estilo propio que se caracteriza por una estética en la que el montaje y los movimientos de cámara producen efectos visuales surrealistas. En esta misma línea, Nikolaidis en su Evridiki BA 2037 se toma la libertad de modificar drásticamente el mito y experimentar con diversos recursos cinematográficos, tales como la planimetría y las secuencias temporales mediante flashbacks y flashforwards, con el objetivo de mostrar el sufrimiento que causa la imposibilidad de recordar. En el caso Parking, Demy muestra una visión particular de la sexualidad y del infierno, en el que predominan las tonalidades blanca, negra y roja cuando la acción se desarrolla en aquel lugar. En cuanto a Shredder Orpheus de McGinley, tanto los personajes deformes como la basura y los desechos metálicos usados para hacer música punk acentúan las precarias condiciones de vida de un ambiente postapocalítptico. Asimismo, los personajes infernales están identificados por un maquillaje lúgubre que acentúa su ausencia de humanidad.

Para finalizar, consideramos que las posibilidades de interpretación del mito, ya advertidas en la Antigüedad, y la flexibilidad creativa y plástica del Séptimo Arte han hecho posible la puesta en pantalla de uno de los episodios míticos más famosos desde distintas perspectivas y con finalidades tan diversas. Los temas del mito como el amor, la pérdida de un ser amado, el duelo y la muerte son universales y pueden adaptarse y actualizarse a cualquier situación, pues dichos temas están ligados indisolublemente al ser humano, por los que se atreve a 'descender' en medio de las peores circunstancias para desafiar las barreras físicas y temporales que supone la muerte. 
BYZANTION NEA HELLÁS Nº 38 - 2019: 49 / 73

\section{Cuadro sinóptico}

\begin{tabular}{|c|c|c|c|c|}
\hline AÑO & TÍTULO & DIRECTOR & GUION & PAÍS \\
\hline 1950 & Orphée & Jean Cocteau & Jean Cocteau & Francia \\
\hline 1959 & Orfeu Negro & Marcel Camus & $\begin{array}{c}\text { Marcel Camus, } \\
\text { Jacques Viot }\end{array}$ & $\begin{array}{l}\text { Brasil, } \\
\text { Francia, } \\
\text { Italia }\end{array}$ \\
\hline 1960 & $\begin{array}{c}\text { The Fugitive } \\
\text { Kind }\end{array}$ & Sidney Lumet & $\begin{array}{c}\text { Meade Roberts, } \\
\text { Tennessee } \\
\text { Williams }\end{array}$ & $\begin{array}{l}\text { Estados } \\
\text { Unidos }\end{array}$ \\
\hline 1975 & 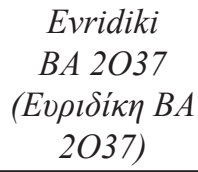 & $\begin{array}{c}\text { Nikos } \\
\text { Nikolaidis }\end{array}$ & Nikos Nikolaidis & $\begin{array}{l}\text { Grecia, } \\
\text { Alemania } \\
\text { Occidental }\end{array}$ \\
\hline 1985 & Parking & Jacques Demy & Jacques Demy & Francia \\
\hline 1990 & $\begin{array}{l}\text { Shredder } \\
\text { Orpheus }\end{array}$ & $\begin{array}{c}\text { Robert } \\
\text { McGinley }\end{array}$ & Robert McGinley & $\begin{array}{l}\text { Estados } \\
\text { Unidos }\end{array}$ \\
\hline 1990 & $\begin{array}{c}\text { Orpheus } \\
\text { Descending }\end{array}$ & Peter Hall & Peter Hall & $\begin{array}{l}\text { Estados } \\
\text { Unidos }\end{array}$ \\
\hline 1995 & 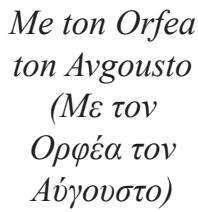 & $\begin{array}{c}\text { George } \\
\text { Zervoulakos }\end{array}$ & $\begin{array}{l}\text { Nikiforos } \\
\text { Markakis, } \\
\text { George } \\
\text { Zervoulakos }\end{array}$ & Grecia \\
\hline 1999 & Orfeu & Carlos Diegues & $\begin{array}{c}\text { João Emanuel } \\
\text { Carneiro, Carlos } \\
\text { Diegues }\end{array}$ & Brasil \\
\hline 2012 & $\begin{array}{c}\text { Vous n'avez } \\
\text { encore rien } \\
v u\end{array}$ & Alain Resnais & $\begin{array}{l}\text { Alain Resnais, } \\
\text { Laurent Herbiet, } \\
\text { Jean Anouilh }\end{array}$ & Francia \\
\hline
\end{tabular}




\section{REFERENCIAS BIBLIOGRÁFICAS}

ARRIETA DOMÍNGUEZ, D. (2014). Palimpsesto y carnavalización: El Orfeu negro de Marcel Camus. Cuadernos de Filología Clásica. Estudios Latinos, 34(1), 131-142.

BAKHTIN, M. (2003). La cultura popular en la edad media y en el renacimiento. Madrid: Alianza.

BERNSTOCK, J. E. (1991). Under the Spell of Orpheus. The Persistence of a Myth in Twentieth-century Art. Carbondale: Southern Illinois University Press.

CADVID, Á. (2001). La búsqueda de lo propio en el cine hispanoamericano. Íkala, revista de lenguaje y cultura, 6(11-12).

CAILlARD, G. (2012). Vous n'avez encore rien vu. Réminiscences. Séquences(282), 58.

CARNEIRO ARAÚJO, P. (2016). Ekoidé no Sambódromo: Segredo ritual, candomblé e espaço público no carnaval paulistano. Revista de Antropologia, João Pessoa, 2(3), 13-36.

COCTEAU, J. (2015). Poética del cine. Buenos Aires: El cuento de plata.

CROCCI DA GRAÇA, M. C., \& MÍNGUEZ BAÑOS, A. (1995). Orfeo y Eurídice: algunas versiones del mito a través de la historia de las artes. EClás, 107, 63-68.

CROWTHER, B. (15 de abril de 1960). Screen: 'Fugitive Kind'. New York Times. DARREN, W. (2016). Jacques Demy. Manchester; New York: Manchester University Press.

EHRLICH, L. C. (2003). Orpheus on Screen: Open and Close Forms. En S. Brent Plate (Ed.), Representing Religion in World Cinema. Filmmaking, Mythmaking, Culture Making (págs. 67-87). New York: Palgrave Macmillan.

FOTIOU, M. (2014). The Cinematic Work of Nikos Nikolaidis and Female Representation (Tesis doctoral). Glasgow: School of Culture and Creative Arts, College of Arts, University of Glasgow.

FOTIOU, M., \& FESSAS, N. (2017). Greek Neo-Noir: Reflecting a Narrative of Crisis. FILMICON: Journal of Greek Film Studies(4), 110-137.

FRIEDMAN, J. B. (2000). Orpheus in the Middle Ages. New York: Syracuse University Press.

GENETTE, G. (1989). Palimpsestos. La literatura en segundo grado (Prmiera edición francesa, 1982 ed.). (C. Fernández Prieto, Trad.) Madrid: Taurus.

GENETTE, G. (2001). Umbrales (Primera edición francesa, 1987). (S. Lage, Trad.) México D. F.; Buenos Aires: Siglo XXI.

GONZÁLEZ DELGADO, R. (1999). El mito clásico en el cine: Orfeo Negro de M. Camus. El cine: otra dimensión del discurso artístico, 1, 331-341. 
GONZÁLEZ DELGADO, R. (2001). El mito de Orfeo y Eurídice en la literatura grecolatina hasta época medieval (Tesis doctoral). Oviedo: Universidad de Oviedo, Departamento de Filología Clásica y Románica.

GONZÁLEZ DELGADO, R. (2008). Orfeo y Eurídice en la Antigüedad. Mito y literatura. Madrid: Ediciones Clásicas.

GRAVES, R. (1985). Los mitos griegos. (L. Echávarri, Trad.) Madrid: Alianza.

LEE, M. O. (1961). Orpheus and Euridice: Some Modern Versions. CJ, 56, 307313.

LEITE, M. P. (2008). Pobreza y exclusión en las favelas de Río de Janeiro. En A. Ziccardi, Procesos de urbanización de la pobreza y nuevas formas de exclusión social. Los retos de las políticas sociales de las ciudades latinoamericanas del siglo XXI (págs. 213-247). Bogotá: Siglo del Hombre CLACSO.

MUlligAN, G. (2017). The Queer Cinema of Jacques Demy (Tesis doctoral). Coventry: Department of Film and Television Studies, University of Warwick.

PALMER, R. B., \& BRAY, W. R. (2009). Hollywood's Tennessee. Austin: University of Texas Press.

PENCAK, W. (1999). Lyres against the Law: Orpheus as Cyberpunk Outlaw. Legal Studies Forum, 23, 293-313.

RODRÍGUEZ, V. J. (2010). La revisión del mito de Orfeo en Tennessee Williams - Orpheus Descending. Espéculo. Revista de estudios literarios. Universidad Compluense de Madrid.

ROSTAGNI, A. (1964). Storia della letteratura latina. II: L'impero. Parte prima: da Augusto a Nerone. Torino: UTET.

SCHIDLOW, J. (1985). Orphée tournage. Télétrama, 13(March).

SCHILliNG, M. (5 de abril de 2013). Sakura, Futatabi no Kanako (Orpheus' Lyre). The Japan Times, pág. https://goo.gl/KGRC5t.

SUMMERS, S. N. (1993). The Orpheus Legend in Literature, Music, and the Visual Arts: Ffour Twentieth Century Works (Tesis doctoral). Texas: Texas Tech University.

TRÉMOIS, C.-M. (2012). Vous n'avez encore rien vu, d'Alain Resnais. Esprit, Décembre(12), 129-134. 